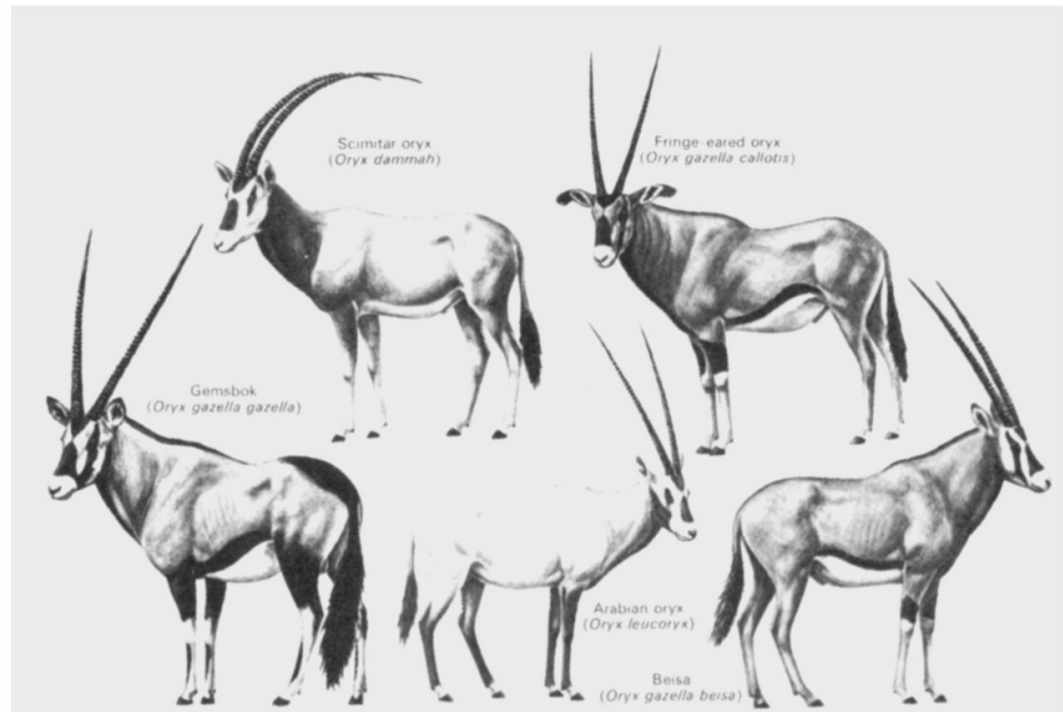

THE THREE ORYX SPECIES-an illustration in Africa: World of Wildlife, reviewed below. Some authorities regard the gemsbok as a separate species, making four.

of the coucal. This is a book for young and old alike, especially those conversant with the African scene.

Dr de la Fuente's second volume contains such a medley of information, some scarcely relevant, as to be positively bewildering and confusing. The title is misleading as both volumes are based on East Africa, and most of the reviewer's criticism of the first volume (Oryx, October 1973) is valid for this one, though the elephant and rhinoceros are now allotted 63 pages, well illustrated in colour. The subject matter evidently was not submitted to the authoritative scrutiny of someone familiar with East Africa. A discourse on vertebrates and invertebrates is marred by inaccuracies. It seems this valuable reference work attempts too much, but certainly it is most informative, as well as profusely and beautifully illustrated in colour, and at $£ 3$ it is remarkable value.

C. R. S. PITMAN

The Predatory Behaviour of Wild Chimpanzees, by Geza Teleki. Bucknell University Press, \$15.

Since Jane Goodall first observed chimpanzees killing and eating prey in 1963 , it has gradually become apparent that this was no isolated incident. Animal food represents a small-but significant-part of the chimpanzee diet. Teleki provides a graphic and detailed account of this predatory behaviour. His study relates exclusively to the Gombe Stream study area, and it is based on a ten-year collection of records together with one year's intensive observations of his own.

So far, the chimpanzees at Gombe have been seen to kill and eat olive baboons, colobus monkeys, red-tail monkeys, blue monkeys, bushback and bush pig, and it is noteworthy that four of these six prey species are actually primates themselves. In sifting past records and adding his own concentrated observations, Teleki has clearly shown the importance of keeping detailed field notes on a wide range of topics and making these available to subsequent observers. The foresight of earlier workers at Gombe has really produced results. Apart from this careful attention to detailed records, it also emerges from Teleki's book that there has been a 
vital shift in emphasis of the work at Gombe over the years; the research workers there are no longer studying chimpanzees alone; they are gradually coming to study an entire ecosystem. This underlines the fact that conservation does not merely entail the protection of single species. At Gombe, for instance, it would be necessary to protect the prey as well as the chimpanzees themselves in order to maintain the natural situation.

The study also clearly shows the dangers of artificial feeding of wild animals ('provisioning') as a means of rapidly reducing their fear of man. There is a strong possibility that the provision of bananas at Gombe increased contact between chimpanzees and baboons and thus led to exaggeration of the normal level of predation on baboons.

This excellent book is a strikingly good example of a well-planned and conducted field-study. The text is well-written and thoughtful, with an abundance of good photographs, charts and maps. In short, the author has reached a standard of excellence which is comparatively rare in recent books on primates. It is entirely apt that there should be a foreword by $C . R$. Carpenter, who is justly regarded as a pioneer of primate field-studies.

The relevance of chimpanzee predation to the development of hunting in early man has yet to be fully explored. However, Teleki clearly brings out a paradox which may eventually prove to be of central interest: Despite continued predation, the chimpanzees continue to have tolerant mutual interactions with the baboons, and the baboons do not attack the chimps with their potentially lethal canines even when predation is taking place. In the interpretation of this clue to the early origins of human hunting behaviour, Teleki's monograph will be a major landmark.

R. D. MARTIN

\section{Large Mammals of West Africa, by D. C. Happold. Longman,} $75 \mathrm{p}$.

Dr Happold's book comes at a very important time for wildlife conservation in West Africa, for which he makes a strong case. In his chapters on identification, distribution, habits, food and status he builds up his reader's enthusiasm and appreciation for the seventy large mammals, both common and rare, including those in danger of extinction.

In his useful introduction he indicates the link between the book and its companion volume, Small Mammals of West Africa by A. M. Booth, which appeared in 1960, and on page 77 he provides a useful page reference summary of information in that book, making it easy to use the two books together.

The general public of West Africa is largely ignorant of its wildlife and is of very limited help to the inquiring visitor. The section on how to use the book is most valuable to both the resident and the visitor, and the vernacular names add appreciably to the book's value. For the rural people the text is within the competence of most of the general reading public, while at the same time police, customs officers as well as foresters and game wardens who have to enforce conservation laws, and lawyers and magistrates, will find the book an excellent guide to identifying the species that are being smuggled under their noses due to their ignorance of the facts. Teachers and students at all levels of education who have to do more and more with ecology will find the book very useful. It is a must for the visitor.

Sixty-eight of the seventy large mammals covered are illustrated in colour or black and white photographs-the two missing ones, the Cameroon otter Paraonyx microdon and the blue duiker Cephalophus monticola are admittedly rare, but even a sketch would have been welcome.

Dr Happold describes the reserves where large mammals are being conserved with a plea for the establishment of more such areas to cover all 